Sir,

\section{Detection of prednisolone in vitreous following systemic administration}

Systemic prednisolone is given for inflammatory conditions of the posterior segment, ${ }^{1}$ though its vitreous penetration has not been demonstrated. To determine whether prednisolone gains access to the vitreous, we obtained a vitreous sample from a patient who had received oral prednisolone $2 \mathrm{~h}$ previously.

\section{Methods}

Following informed consent, $60 \mathrm{mg}$ of oral prednisolone was given prior to the removal of a choroidal neovascular membrane. Neat vitreous samples were obtained from the study patient and from a control patient; the samples were transported immediately to the laboratory on dry ice.

Prednisolone was measured by radioimmunoassay after solvent extraction. The intra-assay imprecision is $6.3 \%, 6.4 \%, 2.8 \%$ and $8.9 \%$ at $8.7,17.4,34.8$ and 69.5 $\mathrm{nmol} / \mathrm{l}$. The accuracy of this method has been confirmed by high-performance liquid chromatography. The crossreaction of this assay with cortisol is $7 \%$ and, therefore, samples are run in a cortisol ELISA assay (Enzymun Test, Boehringer, Mannheim) which has an intra-assay imprecision of $10.7 \%$ and $3 \%$ at 68 and $800 \mathrm{nmol} / \mathrm{l}$. Prednisolone cross-reacts in this assay by $60 \%$ and this is corrected for by simultaneous equation. This method was developed at, and is in current use at, St Thomas' Hospital, London.

\section{Case report}

\section{A 30-year-old woman with punctate inner}

choroidopathy underwent vitrectomy with removal of choroidal neovascular membrane (CNVM) left eye (LE). She had been treated with systemic steroids for active ocular disease but had been off therapy for 120 days preceding surgery.

Pre-operative vision was 6/9 right eye and 6/36 LE due to subfoveal CNVM. Two hours before surgery she was given a single dose of $60 \mathrm{mg}$ oral prednisolone. Pars plana vitrectomy was performed in a standard fashion. Manual aspiration was used to obtain a neat vitreous sample via a $2 \mathrm{ml}$ syringe connected to the tubing. A control vitreous sample was obtained in a similar fashion from an eye undergoing routine pars plana vitrectomy for epiretinal membrane removal in which the patient had not been treated with prednisolone either pre-operatively or in the past.
Vitreous prednisolone levels were $850 \mathrm{nmol} / 1$ in the study vitreous sample and no prednisolone was detected in the control vitreous sample.

\section{Discussion}

Posterior segment penetration of systemically administered steroids is assumed based on response, but has not been documented. ${ }^{1}$ Plasma prednisolone availability $^{2}$ and pharmaco-kinetics ${ }^{3}$ are well described. Levels of topically administered prednisolone in the anterior chamber have been studied, ${ }^{4}$ as has clearance of triamcinolone after intravitreal administration. ${ }^{5}$ Studies of intraocular availability following systemic administration have not been done.

Systemically administered drugs become available in the posterior segment when ocular inflammation results in breakdown of the blood-ocular barrier. Although our case had no evidence of active ocular inflammation, we demonstrated prednisolone in the vitreous. We acknowledge that steroid could have been trapped in the vitreous following prior systemic therapy but steroid clearance after intravitreal injection has been studied and no drug is detectable after 41 days. ${ }^{5}$ Serum prednisolone levels reach a rapid peak and then fall rapidly when therapy is discontinued (half-life $=3 \mathrm{~h}$ ). Serum levels are unmeasurable by day $2 .{ }^{3}$ Continuing transfer from serum to vitreous could not have occurred once systemic therapy was discontinued. Our patient had been off steroids for 120 days; therefore, the measured vitreous steroid must have come from the single pre-operative dose. , $^{3,5}$

This report implies that significant concentrations of systemically administered prednisolone are reached in the vitreous following resolution of active ocular disease. The blood-ocular barrier appears to remain sufficiently permeable to achieve adequate vitreous steroid concentrations following dosing with high-dose steroids delivered orally, and this may have implications for the dose as well as the method of steroid delivery to the posterior segment of the inflamed eye.

None of the authors has any proprietary interest in any substances used in this report.

\footnotetext{
References

1. Gordon DM. Prednisone and prednisolone in ocular disease. Am J Ophthalmol 1956;41:593-600.

2. Morrison PJ, Bradbrook ID, Rogers HJ. Plasma prednisolone levels from enteric and nonenteric coated tablets estimated by original technique. Br J Clin Pharmacol 1977;4:597-603.
} 
3. Frey BM, Frey FJ. Clinical pharmacokinetics of prednisone and prednisolone. Clin Pharmacokinet 1990;19:126-46.

4. McGhee CNJ, Noble MJ, et al. Penetration of topically applied prednisolone sodium phosphate into human aqueous humour. Eye 1989;3:463-7.

5. Schindler RH, Chandler D, Thresher R, Machemer R. The clearance of intravitreal triamcinolone acetonide. Am J Ophthalmol 1982;93:415-7.

Christina J. Flaxel ${ }^{1,3}$

Michael J. Wheeler ${ }^{2}$

Bridget Mulholland ${ }^{1}$

Zdenek J. Gregor ${ }^{1}$

${ }^{1}$ Moorfields Eye Hospital London, UK

${ }^{2}$ Department of Chemical Pathology

St Thomas' Hospital

London, UK

${ }^{3}$ Current address:

University of Southern California

Doheny Eye Institute

Los Angeles

California, USA

e-mail: flaxelcj@aol.com

Zdenek J. Gregor, FRCS, FRCOphth

Moorfields Eye Hospital

City Road

London EC1V 2PD, UK

Tel: $+44(0) 1712533411$

Fax: +44(0)1712534696

Sir,

Occult giant cell (temporal) arteritis presenting with bilateral sixth and unilateral fourth nerve palsies Giant cell arteritis is regarded as the 'prime medical emergency in ophthalmology, there being no other disease in which the prevention of blindness depends so much on prompt recognition and early treatment' ${ }^{1}$ We describe one occult manifestation, namely bilateral sixth and unilateral fourth nerve palsies with no systemic malaise.

\section{Case report}

An 80-year-old man presented with a 2 week history of intermittent pain below the right eye. He had had a trabeculectomy performed previously on the left eye for chronic open angle glaucoma. Topical medication was timolol and dorzolamide b.d. to both eyes. He had noticed diplopia for the past 3 days. He had no systemic malaise, headache, or jaw or lingual claudication.

Best corrected visual acuity was $6 / 9$ bilaterally. Ocular movements were limited laterally in either eye. A Hess recording suggested bilateral sixth nerve palsies (Fig. 1a). Pupil reactions were normal. Intraocular pressure was $24 \mathrm{mmHg}$ in each eye. A left trabeculectomy bleb and iridectomy and glaucomatous optic discs were noted. There was no evidence of anterior ischaemic optic neuropathy. Erythrocyte sedimentation rate (ESR) performed on presentation was $132 \mathrm{~mm} / \mathrm{h}$.

The next day a right temporal artery biopsy was performed. This showed a mixed inflammatory infiltrate affecting all sections of the artery wall but was most marked in the media of the vessel (Fig. 2). Although no giant cells were seen, the pathologist felt the appearance was suggestive of temporal arteritis. The patient was commenced on oral prednisolone $80 \mathrm{mg} /$ day. The following day his eye pain had gone. After 3 days a repeat Hess chart demonstrated that a right fourth nerve palsy had developed in addition to his bilateral sixth nerve palsies (Fig. 1b). His steroid regime was slowly reduced and 2 months following admission he was on 10 $\mathrm{mg} /$ day of oral prednisolone, his ocular nerve palsies had resolved and his ESR was $35 \mathrm{~mm} / \mathrm{h}$.

Other investigations performed before oral steroid treatment was commenced included a full blood picture, urea and electrolytes, liver function tests, autoimmune screen, anti-neutrophil cytoplasmic antibodies, C-reactive protein, serum immunoglobulin assay and serum electrophoresis, chest radiograph and a CAT scan of the brain. Abnormal results included the C-reactive protein, which was markedly elevated at $7.4 \mathrm{mg} / \mathrm{dl}$ (normal range $<1 \mathrm{mg} / \mathrm{dl}$ ); the leucocytes, marginally elevated at $11.4 \times 10^{3} / \mu \mathrm{l}$ (normal range $4-11 \times 10^{3} / \mu \mathrm{l}$ ); and the serum electrophoresis, which showed an elevation of the alpha- 1 and alpha- 2 globulins consistent with an increase in acute phase reactants. Results of other investigations were normal.

\section{Comment}

Patients with giant cell arteritis may present with no systemic complaints, as in this case. The incidence of occult giant cell arteritis has been reported as between $8 \%$ and $38 \%$ of cases. $^{2,3}$

The commonest ocular presentation is anterior ischaemic optic neuropathy, ${ }^{4}$ but many other ocular complications may be produced including retinal artery occlusion, choroidal ischaemia, anterior segment ischaemia and even orbital infarction resembling orbital cellulitis. 5

Ocular motor palsies are recognised in giant cell arteritis ${ }^{5}$ with the oculomotor (III) nerve most commonly involved. ${ }^{7}$ Abducens (VI) or trochlea (IV) nerve palsies are less frequently described. ${ }^{7}$

The occurrence of bilateral abducens (VI), and subsequent trochlea (IV), nerve palsies with no associated systemic malaise is a very rare presentation of giant cell arteritis. It was the initial ESR of $132 \mathrm{~mm} / \mathrm{h}$ that suggested to us giant cell arteritis might be the underlying diagnosis. This was confirmed by checking C-reactive protein levels and performing a temporal artery biopsy. A space-occupying lesion and a systemic vasculitis were excluded by CAT scan and vasculitic screen respectively.

An elevated ESR in combination with a C-reactive protein level of $>2.45 \mathrm{mg} / \mathrm{dl}$, as in this case, has been shown to have a $97 \%$ specificity for the diagnosis of giant cell arteritis. ${ }^{8}$ This high specificity depends on a consistent clinical picture for giant cell arteritis, as 